\title{
Bill Gates, How to Avoid a Climate Disaster: Solutions We Have and the Breakthroughs We Need
}

\author{
(Alfred A. Knopf, 2021) 257 pp., ISBN: 978-0735280441
}

Mark Maslin ${ }^{1}$

Published online: 20 May 2021

(C) Springer Science+Business Media, LLC, part of Springer Nature 2021

When one of the richest men in the world writes a book, people usually take notice. When it is Bill Gates a leader of the tech revolution and it is about climate change, then it becomes a phenomenon. So why has Bill Gates become passionate about climate change and now sees it as the greatest threat to humanity? It all starts with his work with his wife Melinda at the Gates Foundation which was originally focused on global health, development and US education. Two important facts emerged from the funded work of the Gates Foundation. First was that global health and development were being held back by a lack of access to affordable energy: 860 million people still have no access to electricity - which raises the question how to produce this electricity. Second was that all the improvements in global health could be wiped out by climate change- which will increase both food and water insecurity for billions of people. So, Bill Gates went on a journey of discovery and like all super-nerds wanted to find the most efficient technological solutions to the climate crisis.

It is important to remember that this book is not just rhetoric: Bill Gates is putting his money where his mouth is, both through his Foundation and the company he founded, Microsoft. For the great monolithic global corporation, Microsoft is following his lead and taking climate change seriously. In 2020, the company announced the ambitious target to go carbon negative by 2030. Even more ambitiously, it has pledged to remove all the carbon pollution from the atmosphere that they and their supply chain have emitted since the founding of the company in 1975 by 2050 . But here is the issue; their current plan to reach these targets is to reduce their emissions as much as possible, but then to discount the rest of their emissions by using carbon offsets or credits. Basically, Microsoft will pay others to use renewable electricity, plant trees or biofuels, restore nature or capture carbon dioxide directly from power stations or the atmosphere and dump it deep in the Earth. Many NGO and academics are highly critical of carbon offsets as it does not solve the fundamental issue of producing the emissions in the first place and allows companies to buy their way out of their environmental responsibilities. ${ }^{1}$

Bill Gates's book, How to Avoid a Climate Disaster, clearly follows the zeitgeist and is based on the fundamental principle that the world must get to net zero carbon emission by 2050 or earlier if possible. In fact, there is a whole chapter call "Why Zero". This principle needs some unpacking. Net zero carbon emissions means that there will be no increase in atmospheric carbon dioxide by 2050 - and if there are any emissions, these must be balanced by carbon dioxide being sucked out of the atmosphere either by technology or by planting vast forests, hence the term 'net'. What Bill Gates glosses over is that even if we reach net zero carbon by 2050 , the science clearly shows we must have negative emissions for the rest of the century if we are to have any hope of keeping global temperatures below the $2{ }^{\circ} \mathrm{C}$ limit set by world leaders in Paris in 2015. To try to make the net zero carbon target understandable, Bill Gates refers to the current 51 billion tons of carbon emitted per year as a way of illustrating all the things we need to do to reduce this huge number and eventually hit zero. Chapter 4 addresses $27 \%$ of the 51 billion tons and is about our production and use of electricity: it examines how we can decarbonise electricity production and accelerate the uptake of renewables. Chapter 5 covers $31 \%$ and mainly focuses on the production of concrete which if it were a country it would the 6th largest emitter in the world. Chapter 6 represents $19 \%$ and concerns itself with agriculture and deforestation: it explores how we can produce food more efficiently, with less environmental destruction and greenhouse gas emissions. Chapter 7 analyses how we transport ourselves and our goods around the world which makes up $16 \%$ of the total tons of carbon

\footnotetext{
$\overline{1}$ https://trove-research.com/research-and-insight/the-global-voluntary-carbon-market-dealing-with-the-problem-of-historic-credits-dec-2020/.
} 
emitted: it looks at ways of removing fossil fuels from vehicles, ships and aircraft - though the latter two only get two pages in the book because they are so difficult. Finally, chapter 8 analyses the remaining 7\%, looking at how we heat and cool our buildings - for example, how we will need to shift from natural gas to electricity for heating our homes. He acknowledges that the effort to make all of these changes will be hard and in each chapter the book presents some of the available technological solutions - with an occasional suggestion that we should do less of those things which create the most carbon emissions.

The book comes at the right time as there are encouraging signs for the first time in over a decade. In June 2019, the UK parliament amended the 2008 Climate Change Act to requiring the government to reduce the UK's emissions of greenhouse gases to net zero by 2050. In the midst of the pandemic, in April 2021, the UK announced an interim reduction target of $78 \%$ in carbon emissions by $2035-15$ years earlier than previously planned. In addition, the European Commission announced that the EU would reduce its greenhouse gas emissions by at least $55 \%$ from 1990 levels by 2030 , instead of the $40 \%$ cut agreed 6 years ago. This is a major step towards the EU's overarching pledge of carbon neutrality by 2050 . In September 2020, President Xi Jinping announced via videolink to the UN General Assembly in New York that China would aim to reach peak emissions before 2030 , followed by a long-term target to become carbon neutral by 2060 . China is the world's largest carbon emitter, accountable for around $28 \%$ of global emissions, and up to now has not committed to a long-term emissions goal. ${ }^{2}$

In 2021, the USA is the second largest producer of around 15\% of global emissions. After the Trump dispensation, President Biden has re-engaged the USA in the Paris Agreement and has become a strong advocate of collective international action to deal with climate change. In 2021, the USA announced a target cut of $50 \%$ of its carbon emissions by 2030 and pledged to reach net carbon zero by 2050 . Biden has also reinstated the environmental regulations removed by Trump, put in major policies to cut greenhouse gas emissions and greatly increased federal funding for renewable energy and the US green economy. It is clear in the second half of Bill Gates's book that he is addressing the US audience, as we have a whole chapter dedicated to showing why government matter. A gentle counter or push back against the neoliberal agenda of the last 40 years. He uses positive examples of how governments have made environmental policies that have saved lives such as the UK Clean Air Act after the killer smog of the 1950s. He stops short of showing how states influence the aspirations of civil society through the rule of law and the

\footnotetext{
${ }^{2}$ Mark A. Maslin "The road from Rio to Glasgow: A short history of the climate change negotiations", Scottish Geographical Journal, 136:1-4, 5-12, DOI:10.1080/14702541.2020.1853873.
}

development of policy. But he does show how they can use incentives, subsidies, taxation and regulation to help countries, particularly the USA, go carbon neutral. What many people do not realise is that governmental power and policy are the major drivers of innovation, through investment in university research, funding industrial R\&D and driving demand through incentives.

The book finishes with a disappointing chapter on what individuals can do-which is not very inspiring. It says all the right things - talk about climate change, engage with your local politician, use your consumer power to buy renewable energy and sustainable goods, buy an electric car and try a plant-based burger (his way of suggesting we all need to go vegetarian or vegan!). These are covered in just 4 pages-like people are an afterthought to a billionaire. Admittedly, individual actions will only make a small contribution to the overall carbon reductions needed, but they are extremely important as they send a strong message to both government and corporations that citizens want and support major changes. Individual action has had an impact. The School Climate Strikes and the Extinction Rebellion protests have brought together diverse groups of people across the world, all wanting governments to start taking the protection of our planet seriously. And change is starting to happen, with over 1400 local governments and over 35 countries having declared that we are in a climate emergency. But Bill Gates's book is very bland when it comes to politics and there is no mention of public agitation or protests about saving our planet.

Bill Gates includes an afterword on COVID-19 and how he sees it as a major setback for the climate change and global health agenda. While the shutdown of many sectors of the economy has had environmental benefits in terms of carbon emissions and biodiversity loss, few would argue that the socio-economic cost can be justified. But Bill Gates misses the key point that the global lockdown had only a minimal effect on our carbon emissions. A recent study suggests a drop of just $7 \%$ in carbon emissions occurred in $2020 .{ }^{3}$ So, ceasing almost all flying and car journeys has a small impact on our total greenhouse gas pollution. In fact, 2020 global carbon emissions were the same as 2006 . This is because there has been very little change to energy production and agriculture during the pandemic - both major emitters of greenhouse gases. In many ways, this point re-enforces the key chapters of the book that show that energy production, building and manufacturing and agriculture are the greatest emitters of greenhouse gases - none of which changed much during the pandemic.

\footnotetext{
${ }^{3}$ Le Quéré, C., Jackson, R.B., Jones, M.W. et al. Temporary reduction in daily global $\mathrm{CO} 2$ emissions during the COVID-19 forced confinement. Nat. Clim. Chang. (2020). https://doi.org/10.1038/s41558-020-0797-x.
} 
In the afterword, Bill Gates also seems to have missed that the pandemic has change many people's views of and relationship with government and their agencies?. ${ }^{4}$ In response to the COVID-19 crisis, normal governance has been replaced by strong government coordination based on achieving the common good for everyone by managing the rate of new infections through social isolation measures in this severe pandemic, as well as keeping people supplied with food, medication and vaccines. This switch in governance model has not been smooth or quick enough in some countries, with a delayed response in the UK and libertarian resistance in USA and Brazil, which are being counted in bodies. ${ }^{5}$ Recognition of the weakness of some government responses to address the pandemic demonstrates that the majority of people look to governments to address this crisis and now are looking to governments to deal with the bigger climate change crisis.

The book is limited in several important and revealing ways as it does not address the wider environmental and social issues which make dealing with climate change so hard. ${ }^{6}$ For example, global and national structural inequality and the concentration of power and wealth are not mentioned. Oxfam have calculated that the 26 richest people in the world (including Bill Gates) currently own the same amount of wealth as those 3.8 billion poorest people collectively. ${ }^{7}$ When it comes to carbon emissions, $50 \%$ of which are directly related to lifestyle are emitted by the richest $10 \%$ of people in the world. The poorest $50 \%$ of our global society emit just $10 \%$ of the pollution ${ }^{7}$. The book also does not acknowledge the other major environmental disasters that are also occurring such as pollution, deforestation, habitat destruction and extinctions. All of these, like climate change, are caused by our fixation on consumption and the drive by companies such as Microsoft to try and sell us more stuff.

Bill Gates's book is a technophile dream of how to make a better world without a social revolution. Charles C. Mann in his book 'The Wizard and the Prophet ${ }^{8}$ ' uses the story of two ground-breaking American scientists, William Vogt and Norman Borlaug, to illustrate the fundamentally opposing views of the world and our environmental crisis. Norman Borlaug, the Wizard, very much like Bill Gates, regarded

\footnotetext{
$\overline{{ }^{4} \text { Jones, P.J.S. and M. Maslin "Governance of the Global Environmental }}$ Crisis Post-COVID-19" International Affairs Forum The Post-Pandemic World (July) Edition https://www.ia-forum.org/Files/URLMDI.pdf (2020).

${ }^{5}$ Roser, M, Ritchie H., Ortiz-Ospina, E and Hasell J. (2020) https:// ourworldindata.org/coronavirus UN (2020) News. https://news.un.org/en/story/2020/03/1059752.

${ }^{6}$ Simon L. Lewis and Mark Maslin (2018) The Human Planet: How we caused the Anthropocene, (Pelican).

7 Oxfam, Policy Paper - "Confronting Carbon Inequality: Putting climate justice at the heart of the COVID-19 recovery": https:// oxfamilibrary.openrepository.com/bitstream/handle/10546/621052/mbconfronting-carbon-inequality-210920-en.pdf (2020)

${ }^{8}$ Charles C Mann The Wizard and the Prophet: Two Groundbreaking Scientists and Their Conflicting Visions of the Future of Our Planet, Picador 608pp (2018)
}

technology, along with the constant ability of humans to innovate, as a panacea that will cure every ill, whereas William Vogt envisages the future of this planet, as a much darker and more dysfunctional, in which humans have destroyed the environment and superheated the climate. In many ways, when I read Bill Gates's book, it felt like all we need to do is trust in technology and our Star Trek-style future will be assured, whereas many non-billionaires see Blade Runner as the more likely future. I think it is this lack of genuine confrontation with the real human issues in the book that makes it much less powerful than it could have been.

Bill Gates's book is a well-written, clear, factual book which outlines many technological solutions to the use of fossil fuels and proposes new technology required to remove carbon dioxide from the atmosphere. But what his book conspicuously does not do is question the underlying issue of consumer capitalism and its environmental impact. What the book advocates is using the current systems of governance and tweaking them so that they encourage society to decarbonise. It is a book aimed at an American audience to show the scale of the problem but, more fundamentally, to reassure them, there are solutions existing or coming soon which will help avoid the worst of climate change. And yet, this is at odds with the opening and central message of the book, which is we have to go from emitting 51 million tons of carbon emissions per year to zero in less than 30 years. This needs a revolution in our production of energy and food, and in our transport systems, and our built environment. It also needs us to consume less of the planet's valuable and finite resources. We need to radically change our excessive consumption - because we cannot continue as we are, and we certainly cannot in 2050 have 10 billion people with the same consumption habits of an average person in the developed world today. It is the acceptance of the need for this radical change that is so essential if we are to tackle climate change but which is missing from Bill Gates's book.

Publisher's Note Springer Nature remains neutral with regard to jurisdictional claims in published maps and institutional affiliations.

Mark Maslin is Professor of Earth System Science at University College London and author of Climate Change: A Very Short Introduction (Oxford, 2021) and How to Save Our Planet: The Facts (Penguin, 2021)m.maslin@ucl.ac.uk 